\title{
Crime e Estratégias de Policiamento em Espaços Urbanos*
}

\author{
Claudio Beato \\ Bráulio Figueiredo Alves da Silva \\ Ricardo Tavares
}

\section{INTRODUÇÃO}

\begin{abstract}
agenda de prioridades brasileira para a segurança pública, nos A últimos anos, tem circulado em torno da confluência de três grandes temas: 1) criminalidade urbana violenta, em todas as implicações em termos de desagregação e desordem social; 2) espaço urbano, em seus aspectos de exclusão, marginalidade e desorganização;3) polícia, protagonista de múltiplas crises e provavelmente um dos atores mais freqüentes em todas as áreas do espaço urbano.
\end{abstract}

As cifras relativas à criminalidade e à violência nos grandes centros urbanos apontam para a emergência de crimes predatórios. Não obstante o fenômeno do "crime organizado", o que parece estar ocorrendo é o crescimento do crime desorganizado, manifesto nas mais variadas ex-

\footnotetext{
* O projeto sobre o qual este artigo se debruça - Polícia de Resultados - não seria possível sem o apoio da Fundação Ford e da Fundação Hewlett. O Conselho Nacional de Desenvolvimento Científico e Tecnológico-CNPq e o Centro de Estudos Brasileiros da Universidade de Oxford forneceram uma oportunidade ímpar para que um dos autores se dedicasse inteiramente à organização do argumento central deste texto. A Polícia Militar de Minas Gerais, considerando o coronel Severo Augusto da Silva Neto e sua equipe, foi artífice e executora do projeto, protagonizando uma abertura inédita e corajosa aos pesquisadores de uma entidade civil. Renato M. Assunção sugeriu a idéia inicial do artigo. Agradecemos sobretudo a toda a equipe do Centro de Estudos de Criminalidade e Segurança Pública - Crisp, que se dedicou ao projeto durante sua vigência, em especial a Geraldo Majella Moreira Duarte, um dos mais ativos mentores da equipe.
}

DADOS - Revista de Ciências Sociais, Rio de Janeiro, Vol. 51, n-3, 2008, pp. 687 a 717. 
pressões da violência urbana. Esse fenômeno é o pano de fundo da concentração dos crimes violentos nas grandes regiões metropolitanas do país: apenas as regiões metropolitanas de São Paulo e do Rio de Janeiro concentram $40 \%$ dos homicídios no Brasil, embora tenham $18 \%$ da população (IBGE, 2004; DataSus, 2007). Inseparável desse fenômeno está o contexto urbano no qual os crimes ocorrem e que, em boa medida, é responsável por esse crescimento. Cerca de $20 \%$ das mortes violentas acontecem em menos de $2 \%$ da área geográfica dos centros urbanos (Crisp, 2000). Nesse sentido, a violência tem se tornado um dos principais obstáculos ao planejamento e ao desenvolvimento dos grandes centros.

A moderna literatura criminológica destaca fatores da ecologia urbana como um dos elementos relacionados à distribuição espacial de determinados tipos de crime. Em geral, sua distribuição no espaço urbano obedece à Zipf Law, em que poucas regiões concentram grande número de crimes. Em Belo Horizonte, por exemplo, apenas cerca de oito dos mais de 2.500 setores censitários que dividem a cidade respondem por mais de $10 \%$ dos crimes violentos que ocorrem ali. O que está relacionado a esses hot spots? Quais são os determinantes para a ocorrência desses focos de criminalidade (Beato F. et alii, 2005)?

Finalmente, hoje predomina um consenso de que quaisquer que sejam os determinantes socioeconômicos e ambientais, a polícia tem um papel central na prevenção e no controle desses locais. Demandas sucessivas por reformas das polícias que implicam intervenções de ordem constitucional, bem como modernização gerencial, têm surgido nos últimos anos. O núcleo dessas discussões se subdivide em dois argumentos. De um lado tem-se uma questão de princípios acerca do papel da polícia nas sociedades democráticas que se traduz na fórmula sucinta: "Não existe democracia sem uma polícia democrática". O segundo argumento não é enunciado claramente, mas será explorado neste artigo: qual é o impacto da polícia no controle da violência nos centros urbanos brasileiros? A polícia é ator estratégico nas paisagens urbanas, e poucas agências públicas têm penetração tão constante nos mais diversos ambientes de uma cidade, mantendo contato freqüente com seus habitantes em variados estratos.

Cada vez mais as sociedades democráticas demandam organizações policiais transparentes, controladas e eficientes. Nesse sentido, a literatura tem apontado para a importância da adoção de estratégias proa- 
tivas de prevenção e de controle da criminalidade em sociedades democráticas (Goldstein, 1990), em que a gestão de informações que permite alocação focalizada e pontual parece exercer significativo impacto sobre as taxas de criminalidade (Sherman, Gartin e Buerger, 1989; Beato F., 2004a; Beato F., Viegas e Peixoto, 2004).

As imbricações entre polícia, crime e espaço urbano constituirão o cerne da discussão empreendida neste artigo. Busca-se explorar aqui interconexões entre fatores relacionados a essas três dimensões. A pesquisa de hipóteses sobre como esses fatores se relacionam, bem como a maneira como interagem, parece crucial no atual cenário das políticas públicas na área de segurança nos grandes centros urbanos brasileiros.

\section{CRIMINALIDADE E VIOLÊNCIA EM ESPAÇOS URBANOS}

Em sua concepção clássica, as cidades foram criadas justamente para a segurança de seus habitantes, que encontraram ali um espaço de proteção e de liberdade fora dos laços do sistema feudal. O desenvolvimento da cidadania, da racionalidade econômica, de um sistema de leis universalistas e de novas formas de associação entre indivíduos se deu com o crescimento das cidades (Weber, 1978; Durkheim, 1978). Contudo, modernamente, o desenvolvimento dos grandes centros urbanos tornou-se sinônimo de medo e de crime, restringindo de diversas formas a liberdade de seus habitantes e erodindo a sensação de segurança (Davis, 1998). Alguns autores acreditam que cidades não são responsáveis pelos crimes que ocorrem em seu interior, mas apenas palco de relações sociais, estas, sim, responsáveis pela violência (Freitag, 2002). Trata-se de um argumento que negligencia as diversas formas pelas quais essas relações se dão no contexto urbano e as influências ambientais sobre diversos tipos de violência que ali se manifestam. A conformação urbana é o elemento central na desorganização social de comunidades e lugares (Shaw e McKay, 1942), na estrutura de oportunidades para a ocorrência de delitos (Cohen e Felson, 1979) e no mercado habitacional formal e informal como fator incentivador de diversas formas de crime violento e capacidade de auto-regulação (Bottoms e Wiles, 1997). O exame das taxas de crime agregadas em áreas geográficas tem procurado explicar a variação das taxas de crime violento entre várias cidades, áreas metropolitanas, estados ou países (Bailey, 1984; Blau e Blau, 1982; Land, McCall e Cohen, 1990; Schuerman e Kobrin, 1986; Fajnzylber, Lederman e Loayza, 1998). Os resultados têm mostrado que variáveis como índice de desigualdade econômica, estrutura 
populacional, englobando total da população e densidade populacional, e índice de desemprego estão associadas significativamente aos homicídios (Beato F. e Reis, 1999).

Em contraste com essas abordagens que usam variáveis socioeconômicas e individuais agregadas, a compreensão de fatores relacionados ao espaço urbano tem se desenvolvido em virtude do avanço de novas técnicas de análise espacial e da capacidade computacional de análise de grandes bancos de dados. Isso tem permitido a busca de explicações no interior do espaço urbano em um nível de detalhe que não era possível anteriormente. Mais recentemente, em uma retomada da tradição da Escola de Chicago, a dinâmica contextual das comunidades urbanas passa a ser o foco das análises para a compreensão da criminalidade e da violência (Sampson, 2002; Abott, 1997; Beato F., 2001; Beato F. et alii, 1999; Johnson et alii, 1990). A retomada dessa tradição se dá diante da constatação da concentração ecológica de recursos socioeconômicos e de mecanismos de segregação espacial e de concentração de crimes.

Esse modelo ecológico de geração do crime busca a compreensão da natureza multifacetada da violência e a identificação dos fatores que influenciam o comportamento do indivíduo aumentando o risco de que ele cometa violência ou de que seja vítima dela. A análise ecológica das distribuições dos delitos criminais em centros urbanos nos conduz a questões de natureza prática e teórica. A questão é: por que alguns bairros e localidades de uma cidade têm altas taxas de criminalidade? Muitas pessoas gostam de se referir ao fenômeno da explosão da criminalidade em grandes centros urbanos. Mais correto seria falar de implosão, pois ocorre em áreas específicas, no interior das comunidades, onde vítimas e agressores são originários do mesmo espaço e nele coabitam.

Teoricamente, a literatura que lida com a hipótese da desorganização social debita essa maior incidência às características socioeconômicas das comunidades, bairros e vizinhanças (Shaw e McKay, 1942; Park e Burgess, 1924; Bursik Jr., 1986) ou à "eficácia coletiva" no controle do comportamento de seus habitantes (Sampson, Raudenbush e Earls, 1997). Na realidade, esse mecanismo de causação não se dá de forma direta, mas resulta do fato de que áreas com maior privação relativa e absoluta provocam incrementos de mobilidade e de heterogeneidade populacional, conduzindo assim a um enfraquecimento dos laços tra- 
dicionais de controle social e, conseqüentemente, a um maior número de crimes. Contudo, evidências empíricas mostram que existem lugares em uma cidade com uma alta incidência de delitos cuja explicação não se dá apenas pelas características agregadas de suas populações. Existe algo a mais, relacionado às características ambientais, que pode estar favorecendo essa incidência de atividades criminosas. O efeito das vizinhanças (neighborhoods) e locais vão além das características tradicionais relativas à concentração da pobreza para se debruçar sobre aspectos tais como mecanismos institucionais e processos interacionais entre as pessoas. Laços sociais, confiança, recursos institucionais, desordem e atividades rotineiras passam a ser destacados como dimensões explicativas da concentração da violência e da criminalidade (Sampson, Morenoff e Gannon-Rowley, 2002).

Como decorrência desse enfoque, e em contraposição às abordagens que lidam apenas com as características individuais ou de grupos sociais, desenvolveram-se estratégias de análise para lidar com a distribuição espacial de crimes, bem como com contextos de oportunidade para a ação criminosa (Cohen e Felson, 1979). São as características da comunidade e dos espaços urbanos em que os crimes ocorrem que devem ser examinadas. Existe uma produção acadêmica que chama a atenção para o fato de que algumas comunidades mantêm altas taxas de criminalidade apesar de mudanças substantivas nas características sociais e culturais de seus residentes (Shaw e McKay, 1942; Reiss Jr. e Bordua, 1966). Note-se que não se está negando a importância dos fatores de background socioeconômico como elementos que podem predispor alguns indivíduos ao crime. O que ocorre é que eles se tornam apenas um dos elementos na definição do contexto da atividade criminosa. Os outros têm a ver com a disponibilidade de alvos para a ação criminosa, a ausência de mecanismos de controle e de vigilância, e mecanismos de ordem institucional e interativa (Cohen e Felson, 1979). A estratégia dominante privilegiou a análise sociodemográfica e as características sociais de grupos de indivíduos nas cidades, com especial atenção à concentração da pobreza (Wilson, 1987). A comparação entre comunidades de diferentes estratos pode fornecer pistas acerca dos mecanismos e recursos acionados para o controle sobre espaços geográficos e lugares. Exercícios românticos acerca da "cultura cívica" ou do "capital social" são de pouca valia se as condições pelas quais a coesão social das comunidades se traduz efetivamente em controle social do local não forem explicitadas (Pate et alii, 1985; Sampson, 2002). Paradoxalmente, nem sempre essa coesão se traduz em mecanismos de controle e 
na mobilização de recursos em favor da comunidade (Wilson, 1987). Comunidades pobres podem desenvolver mecanismos de interação na vizinhança que não se traduzem necessariamente em eficácia coletiva e conseqüente redução da criminalidade (Zaluar, 1984; Zilli, 2004; Silva, 2004).

Da mesma maneira que fatores ambientais atuam de modo regulatório sobre a incidência espacial dos crimes, o papel da polícia como um ator estratégico no cenário urbano não pode ser ignorado. Isso porque o controle da violência nos espaços urbanos deteriorados dependerá em grande medida das formas pelas quais se dá a atuação da polícia nesses locais.

A próxima seção tratará especificamente do papel da instituição policial no controle da criminalidade, que, embora não sendo exclusividade das polícias, consideramos um dos recursos institucionais de regulação das relações sociais no espaço urbano. As formas pelas quais se dá essa atuação são cruciais para a compreensão de mecanismos que possam auxiliar políticas públicas voltadas para a redução da violência, sobretudo em espaços urbanos deteriorados. Ciente de que o controle da criminalidade não esteja no âmbito exclusivo das polícias, assumimos que a adoção de estratégias e de técnicas proativas e preventivas de policiamento pode exercer um impacto significativo na redução da criminalidade urbana.

\section{O PROBLEMA DAS POLÍCIAS NO BRASIL}

Um dos atores onipresentes nos mais diversos espaços urbanos é a polícia. O grau de capilaridade dessas organizações e a natureza de grande parte de suas atividades levaram-nas a ser definidas como o "serviço social secreto da sociedade" (Muir, 1977). A despeito dos sentimentos ambíguos suscitados pela polícia junto às comunidades pobres, poucas agências públicas têm sido tão demandadas pela população dessas áreas, constituindo-se em serviço público de primeira necessidade. A deterioração acarretada pela implosão da violência nesses locais tem levado essas comunidades a um sentimento de desamparo e de desalento que, associado à precariedade de outros serviços públicos, acaba potencializando o ambiente de desorganização social.

Nesse sentido, surge uma questão crucial para a sociedade: qual é o impacto da polícia sobre as taxas de criminalidade? A polícia pode funcionar como um recurso institucional para as comunidades urbanas 
resgatarem sua capacidade de autocontrole? Regiões degradadas pela violência podem ser recuperadas pelas agências públicas de controle social? Não se trata apenas de aumentar o efetivo policial nessas regiões ou o orçamento gasto com a polícia. Por questões óbvias, o número de policiais não nos diz o que eles estão fazendo nas ruas, da mesma maneira que o incremento no orçamento não significa que estejam adequadamente alocados (Blumstein, Cohen e Nagin, 1978).

Nos Estados Unidos, durante os anos 1970 e 1980, a preocupação consistia em avaliar estilos específicos de policiamento. Uma hipótese era que departamentos de polícia que adotavam estilos mais legalistas tendiam a desenvolver estratégias mais agressivas de policiamento e teriam maior impacto nas taxas de criminalidade (Wilson, 1968; Wilson e Boland, 1982). Isso se daria de forma indireta pelo incremento na probabilidade de prisões por meio de blitze e operações de busca e apreensão. A conseqüência mais importante, entretanto, estava na mensagem enviada pela polícia modificando a percepção acerca das chances de prisão mediante o aumento do custo de se cometerem crimes. Essa forma de comunicação direta minimizava a percepção de desordem e contribuía, portanto, para o incremento dos mecanismos de controle social, em uma antecipação do que viria a ser utilizado posteriormente em Nova York. De fato, avaliações posteriores confirmaram a eficiência do trabalho proativo pela polícia (Sampson e Cohen, 1988).

De qualquer modo, a experiência norte-americana mostrou como a gestão das atividades policiais poderia ser um componente importante na regulação da vida social e, conseqüentemente, no controle da criminalidade (Wilson e Kelling, 1982). Posteriormente, esse componente específico de definição e solução de problemas foi isolado, dando origem a um novo paradigma de policiamento (Goldstein, 1990). No Brasil, apenas recentemente o debate acerca de melhores formas de gestão tem sido incorporado na agenda de reformas possíveis no âmbito das polícias (Beato F., 2001).

Os limites desse impacto ainda não são claros. De um lado alguns autores acreditam que não há muito que ser feito pela polícia em relação ao controle da criminalidade, na medida em que os determinantes fundamentais não estão no âmbito de sua atuação. Segundo alguns autores, utilizar a polícia para resolver o problema do crime seria como lançar mão de "band-Aid para curar câncer" (Bayley, 1994). Os determinantes mais importantes para a prevenção estão sob a responsabilidade de 
outras agências e tipos de programa. De outro lado o paradigma da polícia de Nova York, em relação aos crimes de qualidade de vida, conferiu grande importância às estratégias gerenciais desenvolvidas pela polícia (Kelling e Coles, 1996; Bratton, 1998). Existe uma grande margem de atividades que pode ser desenvolvida pela própria polícia, desde que adequadamente respaldada por informações e formas de gestão mediante resultados.

Portanto, a principal hipótese a ser desenvolvida neste artigo é que, na América Latina, a despeito da enorme magnitude de problemas sociais, a polícia tem um papel central no estabelecimento de políticas preventivas e proativas de controle da atividade criminal predatória nos centros urbanos. Uma política de segurança pública deve lidar, a par das estratégias de desenvolvimento socioeconômicas de âmbito local e focalizado, com mecanismos que incrementem a eficiência e o controle da polícia. É a esse somatório de ações em várias frentes, começando pelo desenvolvimento social até uma gestão do trabalho policial, que se denominará gestão comunitária de problemas de segurança. Trata-se de atividade policial que leve em conta a diversidade dos espaços urbanos para o planejamento de ações, bem como o estabelecimento de metas, conforme veremos a seguir.

\section{GESTÃO COMUNITÁRIA DE PROBLEMAS DE SEGURANÇA PÚBLICA}

Apesar do enorme apelo público por mais controle da criminalidade por intermédio da polícia, não está muito claro qual é a parcela exata que lhe cabe nessa tarefa. A complexidade dos fenômenos com os quais a polícia tem de lidar, bem como a diversidade de contextos urbanos nos quais atua, tem reiterado o descrédito reinante em relação às formas convencionais de atuação policial. Recentemente, cada vez mais vêm se destacando as abordagens que buscam fazer reengenharias institucionais para desenvolver uma gestão por resultados mais consistentes com a atividade policial (Bratton, 1998). Nessa perspectiva, o tratamento da informação e o conhecimento teórico passam a ocupar um papel central nas atividades policiais, que, ao lado de estratégias de envolvimento comunitário e de articulação com outras agências públicas, terminam por delinear o que denominamos aqui gestão comunitária de problemas de segurança pública.

De acordo com essa ótica, informação torna-se o insumo básico para o desenvolvimento estratégico, dados a diversidade e o caráter multifa- 
cetado dos espaços de atuação policial. Daí a necessidade de desenvolver modernos sistemas de gestão das atividades de segurança pública, com a utilização intensiva de informações para fins de planejamento e desenvolvimento de estratégias, além de elaborar planos para monitoramento e avaliação de resultados. Isso envolve aspectos tecnológicos para a organização de diversos níveis da atividade policial e judiciária, com distintas concepções a respeito do armazenamento e do manejo de dados. A tecnologia da informação, para fins de segurança pública, é terreno amplo que se multiplica nas inúmeras aplicações nos âmbitos da investigação, das evidências científicas ou no monitoramento e na vigilância para atividades de inteligência (Manning, 1988; 1992; Skolnick, 1966; Reiss Jr. e Bordua, 1966).

Em adição, o envolvimento comunitário e de outros atores que lidam com o problema da segurança pública é componente essencial nesse tipo de gestão, pois ela deve ser feita em rede e em parceria com essas outras agências (Goldstein, 1990). Em tempos de crise de legitimidade e interação rarefeita com o público, essas parcerias exigem certa reengenharia na formação e no planejamento das atividades policiais. As razões para o desenvolvimento desse tipo de estratégia serão discutidas mais detalhadamente a seguir.

\section{Estratégias Tradicionais de Policiamento}

No caso brasileiro, essa mudança de paradigma implica obstáculos a serem ultrapassados. O primeiro tem a ver com a ausência de uma cultura de planejamento e gerenciamento de problemas de segurança pública, tornando os desafios nessa área equivalentes aos de controlar catástrofes naturais nas quais pouco da intervenção humana faz diferença. A ausência de uma cultura mais arraigada de planejamento tem muito a ver com uma crença que termina corroborada pela escassa formação em projetos sociais de controle e de prevenção da criminalidade ou em políticas públicas de segurança. Do ponto de vista estritamente policial, a crença é de que é possível gerenciar recursos humanos e materiais, mas não o resultado desse processo. Assim, são utilizados velhas técnicas de organização e métodos que possibilitam uma administração interna de quartéis e delegacias, mas jamais de resultados em relação a crimes.

Uma das traduções desse tradicionalismo gerencial nas organizações policiais é amplamente conhecida na literatura como "abordagem por 
incidentes". O professor Goldstein (1990) vê isso como um dos entraves para uma abordagem por resultados nas polícias, pois trata cada evento isoladamente, sem compreendê-lo em uma estrutura de causalidade mais ampla. Sistemas de informação e gerenciamento de viaturas que orientam os atendimentos das ocorrências policiais não estão aptos a relacionar eventos que obedeçam a padrões temporais ou espaciais. Conseqüentemente, o serviço é desarticulado e com pouca inteligência em termos de relacionamento e identificação de padrões.

A ausência de esforço na compreensão de padrões e na análise de casos contribui largamente para a ineficácia e a inércia das organizações de segurança pública e para o conseqüente desalento entre os operadores do sistema. A abordagem "orientada por incidentes" significa basicamente que o acionamento da polícia se dá mediante as chamadas feitas ao teleatendimento emergencial (190) por cidadãos, outras instituições governamentais ou, em menor número, pela própria iniciativa da polícia. O procedimento adotado pelos policiais nesses casos é exatamente o mesmo: tomam nota dos incidentes por meio dos boletins de ocorrência, comunicam-se com a central de operações sobre o que fazer, encaminham-nos aos canais competentes, encerram o incidente e vão embora. A ineficiência nesse estilo de patrulhamento tem a ver com o fato de ele ser alocado de acordo com uma lógica reativa, e não com a dinâmica espacial e temporal dos delitos criminais, de forma preventiva, compreendendo a causa que dá origem a inúmeros incidentes. Recursos são alocados em resposta ao número de eventos já ocorridos nas áreas de policiamento. Uma análise mais detalhada a respeito da incidência de delitos mostraria facilmente como existem dinâmicas distintas para cada tipo de ocorrência, com características-padrão que podem ser identificadas. Os delitos não ocorrem aleatoriamente ou de forma difusa pela cidade.

\section{A Experiência de uma "Polícia de Resultados" e o Controle da Criminalidade em Espaços Urbanos}

A Polícia Militar de Minas Gerais - PMMG é uma organização de tradição e de grande prestígio junto às polícias brasileiras. É referência e pioneira na abertura institucional em relação aos centros acadêmicos e às entidades civis em atividades de formação desde os anos 1980. Essa abertura deu origem a uma geração de oficiais que tornaram possível a introdução de inovações e de experiências importantes nas formas de policiamento no Brasil. 
No final dos anos 1990, um período de grave deterioração das condições de segurança pública no estado brasileiro de Minas Gerais, precedido por uma crise institucional no âmbito das polícias, culminou em uma greve dos policiais e levou a Polícia Militar a iniciar um profundo processo de introdução de inovações no campo gerencial e no relacionamento com a população e outras entidades civis. Parcerias com a sociedade civil e instituições externas fizeram parte de um conjunto de modificações e inovações introduzidas para fazer frente a esse contexto de crise. Um dos componentes foi a assinatura de convênios com universidades, resultando em um processo inédito de parceria no âmbito operacional das atividades policiais. Iniciou-se uma colaboração entre uma organização policial e um centro de pesquisas em políticas públicas. O objetivo era desenvolver tecnologias, análises, bem como incrementar mecanismos de assessorias, desenvolvimento de programas específicos e avaliações das atividades policiais. Para a implementação das inovações pretendidas, um dos componentes principais foi a organização de dados que estivessem disponíveis de forma rápida para o planejamento operacional por meio de estatísticas e de mapeamento ${ }^{1}$. Foi também conferida forte ênfase ao relacionamento da polícia com a comunidade mediante a criação de conselhos comunitários em 25 regiões da cidade. Esses conselhos passaram a ser parceiros ativos na busca de soluções junto à polícia; alguns deles foram capazes de desenvolver parcerias em projetos específicos muito bem-sucedidos, e outros nem tanto ${ }^{2}$.

O projeto Polícia de Resultados foi estruturado em torno de alguns eixos centrais:

a) Descentralização e autonomia de planejamento. A cidade de Belo Horizonte foi dividida em 25 regiões de policiamento (Companhias de Policiamento Militar), que passaram a ser de responsabilidade de gerentes de segurança pública, na figura dos capitães encarregados de cada companhia. Eles eram os encarregados pelos resultados na área sob sua responsabilidade e, para isso, poderiam adotar as medidas que julgassem necessárias. Adotando algumas das técnicas de gerenciamento policial consagradas pela polícia de Nova York, eram realizadas reuniões periódicas nas quais participavam os oficiais encarregados de cada unidade, bem como, eventualmente, algumas lideranças das comunidades. Era solicitado um plano de emprego operacional cuja realização seria objeto de avaliação posterior por parte dos comandantes. A ênfase na gestão por resultados, portanto, constitui-se em uma 
tônica das modificações efetuadas, podendo inclusive levar a uma troca de comandantes de área quando necessário.

b) Uso intensivo de informações. Um dos componentes principais do projeto foi a utilização intensiva de informações oriundas das ocorrências registradas pela PMMG para efeitos de planejamento operacional e desenvolvimento de programas e projetos de controle da criminalidade. Ao contrário da elaboração de relatórios insípidos no final do ano, com objetivos de uma prestação burocrática de contas, buscou-se organizar um centro de análise de crimes que subsidiasse permanentemente os comandantes com informações e análises.

A organização das informações desdobrou-se em duas etapas: a primeira consistiu na organização de bases de dados a serem utilizadas de forma georreferenciada, além do treinamento de analistas de crime. A segunda deveria expandir o universo de usuários do sistema de estatística e de georreferenciamento, alcançando o nível dos operadores de rua da polícia, mediante o treinamento de pessoal para efetuar análises no âmbito das companhias de policiamento.

Para a organização da base de dados que compunha o geoarquivo, foram utilizados: 1) dados do Centro de Operações Policiais Militares Copom - relativos à cidade de Belo Horizonte. Inicialmente alimentado pelo telefone 190 e, posteriormente, sofrendo atualizações fornecidas pelos patrulheiros encarregados do atendimento da ocorrência ${ }^{3} .2$ ) Dados de geoprocessamento produzidos pela Empresa de Informática e Informação do município de Belo Horizonte - Prodabel $^{4}$, órgão da Prefeitura de Belo Horizonte com uma base de dados geográfica com mais de cinco milhões de objetos cadastrados. São arquivos gráficos com representação de informações que vão desde a malha viária até dados físicos, como hidrografia, arborização e topografia da cidade. Para efeitos do projeto, foram utilizados inicialmente os dados referentes aos quarteirões, eixos de ruas, bairros, favelas, áreas verdes, áreas das companhias de policiamento e batalhões, além de informações georreferenciadas sobre alvos de delitos, como bancos, supermercados, mercearias, padarias, casas lotéricas etc ${ }^{5}$.3) Dados do censo de 1991 e da contagem de 1996 para informações socioeconômicas e demográficas relativas aos setores censitários. 4) Dados fornecidos pelas comunidades por meio dos Conselhos Comunitários de Segurança Pública.

c) Formação e qualificação de recursos humanos. A fim de implementar e institucionalizar o projeto, foram treinados, em Análises de Crimes, 23 
policiais que ocupavam cargos em diretorias de planejamento e emprego operacional no âmbito dos batalhões e do Comando de Policiamento da Capital ${ }^{6}-\mathrm{CPC}$. As análises preliminares passaram a ser feitas pelo Departamento de Estatística do CPC, que passou a funcionar, na prática, como uma unidade de análise de crime. A cada seis meses era entregue aos gerentes de cada uma das 25 subáreas (companhias) de policiamento um diagnóstico estatístico das ocorrências de crimes violentos indicando os delitos mais comuns em cada uma das companhias, bem como sua distribuição espacial dentro daquele território. $\mathrm{O}$ diagnóstico estatístico mostrava quais eram os delitos de maior incidência, bairros em que estavam concentrados, horário, dia da semana e mês. Logo a seguir, os delitos mais comuns em cada área foram representados pontualmente em um mapa da região, permitindo a identificação de "eixos" e "manchas" de criminalidade. Inicialmente essa identificação era feita apenas de forma visual, por meio de uma técnica rudimentar de utilização de elipses. Posteriormente foram fornecidas pela universidade diversas outras possibilidades de análise e identificação de hot spots, que passaram a ser denominados pela polícia "zonas quentes de criminalidade- ZQC".

Com base nessas informações, os capitães de cada companhia detalhavam um planejamento de emprego operacional para os meses seguintes, estabelecendo metas de desempenho a serem alcançadas nesse período. Na realidade, os dados estatísticos e de mapeamento eram apenas a ferramenta inicial para a compreensão do que estava ocorrendo nesses locais. Dados de natureza qualitativa deveriam ser colhidos posteriormente junto aos serviços de investigação e de inteligência das polícias com informações complementares a respeito de grupos e pessoas envolvidos com delitos nessas áreas. Além disso, era muito estimulada a solução em parcerias. Nos casos em que havia problemas relacionados a assaltos a ônibus ou a táxis, por exemplo, eram feitas negociações junto aos sindicatos e aos empresários do setor para que soluções conjuntas fossem buscadas.

d) Parceria e gestão comunitária. Outro componente importante era o destino das informações, compartilhadas com membros dos conselhos comunitários, que assim poderiam visualizar mais claramente sua região. Era possível também agregar informações que não chegavam ao conhecimento do sistema de chamadas da polícia. Isso se traduziu no aumento da accountability da organização na medida em que os oficiais tinham de fornecer e explicar as estatísticas à opinião pública por meio 
da imprensa e em reuniões e seminários realizados com a sociedade. A assimilação desse processo de compartilhamento de informações se deu de forma bastante diferenciada entre diversos conselhos da cidade. Alguns fatores contribuíram para o maior ou menor grau de sucesso das atividades de policiamento comunitário, sobretudo em relação às informações utilizadas (Beato F., 2004b). A qualidade das lideranças comunitárias, bem como a dos oficiais, era uma variável de impacto e derivava especialmente da necessidade de formação dos envolvidos no planejamento de policiamento comunitário.

As reuniões de avaliação eram denominadas Encontros de Avaliação e Desempenho Operacional - EADO e ocorriam em uma sala especialmente preparada para esse fim, com recursos de multimídia para a apresentação de mapas e tabelas. O formato foi claramente inspirado no Comparative Statistics - CompStat desenvolvido pela polícia de Nova York ${ }^{7}$. O modelo desenvolvido teve de ser adaptado para a realidade local com importantes diferenças. O objetivo inicial das reuniões teve um caráter mais didático, tratando de transmitir um processo de gestão de atividade policial que era uma completa novidade para os padrões latino-americanos usualmente pouco afeitos a cobranças com base em resultados. A mudança de comandantes pouco produtivos também não é característica das polícias militares brasileiras, com desempenho e mecanismos tradicionais de avaliação que pouco têm a ver com atividades operacionais. Além disso, o verdadeiro ritual de humilhação pública que caracterizou o CompStat de Nova York durante certo período não seria bem-visto pela organização.

\section{Fonte de Dados e Metodologia}

A fim de verificar o impacto da introdução de uma forma de policiamento voltada para a gestão da informação e a busca de resultados, este estudo utiliza uma série mensal de crimes violentos fornecida pela PMMG. O período estudado possui 108 observações e compreende os meses de janeiro de 1995 a dezembro de 2003. Os dados utilizados são os registros sobre crimes violentos contra a pessoa e contra o patrimônio: homicídios, roubos, roubos à mão armada e violências sexuais tentadas e consumadas.

Durante os meses de janeiro de 2001 e outubro de 2002, o CPC da PMMG, após um período de adaptações, iniciou a experiência de gestão descrita anteriormente. Nesse período, foram feitas observações 
das reuniões de avaliação operacional entre os diversos níveis de comando regional na cidade de Belo Horizonte. Os Planos de Emprego Operacional das unidades geográficas também foram objeto de análise. Entrevistas e troca de opiniões com policiais de diversos níveis de comando também se constituíram em fontes.

Após o mês de outubro de 2002, em virtude de mudanças no comando e de orientações no interior da organização, as modificações descritas são abandonadas, ou seja, o período denominado "Polícia de Resultados" perde sua continuidade. Isso nos deu uma oportunidade única de avaliar os resultados de um programa introduzido exclusivamente no âmbito policial, em uma espécie de semi-experimento, permitindo avaliar o impacto da gestão do policiamento adotada na cidade sobre a tendência de criminalidade verificada nos períodos anterior e posterior.

Diante dessa realidade, adotou-se uma técnica de análise de séries temporais com a definição de quebras estruturais para o período em que o programa esteve vigente - "Polícia de Resultados". Divergências de ordem metodológica marcam o debate sobre a efetividade da polícia no controle da criminalidade. Existem estratégias distintas para avaliar esse tipo de intervenção. São estudos longitudinais que avaliam o efeito tido pelo incremento ou decréscimo do número de policiais por habitante sobre as taxas de crime ao longo de certo período de tempo (Loftin e McDowall, 1982) ou análises cross-section comparando diferentes regiões em sua razão de policiais por habitante e as taxas de criminalidade (Kelling et alii, 1974). A utilização de indicadores agregados por análises cross-sections pode dar origem a vieses distintos na análise de resultados. Trabalhar com taxas agregadas em dado momento oculta o comportamento sobre parcelas específicas da população (jovens ou pobres, por exemplo). Outro problema seria a simultaneidade: quando há um incremento de certos tipos de crime, haverá um maior número de ações em direção a ele, gerando a falsa interpretação de uma paradoxal correlação positiva entre polícia e crime (Jacob e Rich, 1980). Isso poderia ser solucionado por meio de análises temporais. Wilson e Boland (1982) por sua vez, argumentam que estudos longitudinais são inapropriados em virtude da limitação em isolar quais efeitos se devem a mudanças político-estruturais. Polícias, ao contrário, tendem a manter certa estabilidade em termos de atuação ao longo do tempo. 
Essa controvérsia passa ao largo da possibilidade de fazer estudos semi-experimentais como este, em que um período de intervenção é claramente delimitado. Entretanto, diversos outros estudos sobre o impacto de formas específicas de policiamento têm sido realizados com o intuito de mensurar o papel que mudanças na gestão do policiamento teriam sobre os índices de criminalidade em diversas cidades, como Newark (Sherman, 1983) e San Diego (Boydstun, 1975).

No caso específico de Belo Horizonte, buscou-se identificar a existência de mudança na tendência mensal de crimes violentos observada no período em que o policiamento tradicional assume uma nova característica, bem como se as alterações feitas na forma de policiamento tiveram impactos significativos nas estatísticas de crimes violentos. O Gráfico 1 a seguir mostra a evolução mensal dos crimes violentos, em Belo Horizonte, no período em estudo, janeiro de 1995 a dezembro de 2003.

Nesse gráfico, as duas linhas verticais internas compreendem o período de intervenção, ou seja, os meses em que se adotou uma nova forma de gestão e de administração. A primeira questão de pesquisa é saber se a mudança na trajetória da série mensal de crimes apresentada

\section{Gráfico 1}

Evolução Mensal de Crimes Violentos

Belo Horizonte - Janeiro de 1995 a Dezembro de 2003

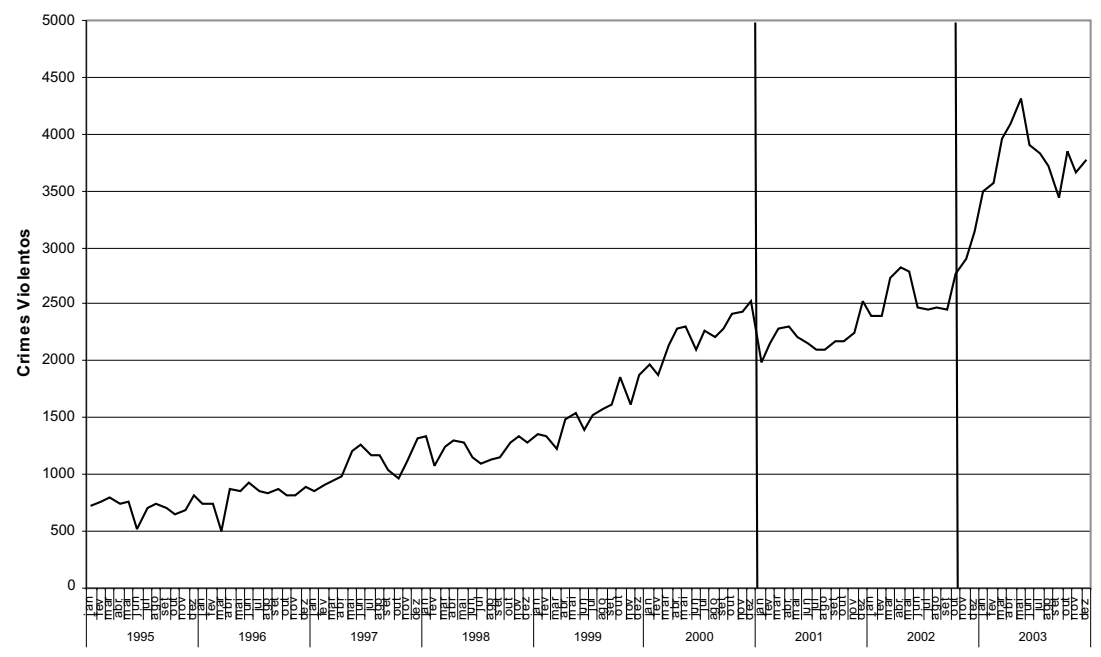

Fonte: Crisp/UFMG. 
no gráfico é estatisticamente significativa para o período de intervenção. Os testes estatísticos mais conhecidos (testes $t, X^{2}$ ou $F$ ) são baseados na suposição de constância dos parâmetros do modelo. Nesta análise, os pontos de mudança que intervieram no comando da polícia são conhecidos: jan./2001 e out./2002. Dessa forma, no caso de pontos de mudança conhecidos, Chow (1960) propôs um teste para averiguar a instabilidade dos coeficientes de um modelo de regressão por meio de um teste $F$ (formulado para mudanças nos parâmetros) conhecido como teste de Chow ${ }^{8}$.

Foi utilizado o procedimento Autoreg do software SAS System@ para executarmos o teste de Chow na série de crimes violentos observada em Belo Horizonte. Os resultados desse teste são apresentados na Tabela 1 a seguir:

Tabela 1

Testando os Pontos de Quebra via Teste de Chow

\begin{tabular}{l|c|c|c|c}
\hline Teste & Pontos de Quebra & Graus de Liberdade & Estatística F & Prob. $>$ F \\
\hline Chow & 73 & 2 & 41,15 & $<0,0001$ \\
Chow & 93 & 2 & 53,60 & $<0,0001$ \\
\hline
\end{tabular}

Elaboração dos autores.

O teste de Chow confirma que as alterações na forma de policiamento realmente foram estatisticamente significativas e, portanto, as observações do período estudado são pontos de quebra. Variáveis indicadoras foram definidas a partir desses pontos de quebra. Para tanto, o procedimento $\operatorname{Reg}$ foi usado para ajustar uma regressão múltipla incorporando as mudanças. O tempo e os períodos de quebra estrutural foram utilizados como as covariáveis desse modelo, e os resultados são apresentados na Tabela 2 a seguir.

Considerando $\hat{Y}$ o número de crimes esperados em determinado tempo $i$, o modelo final pode ser visualizado a partir da expressão seguinte:

$$
\hat{Y}_{i}=31,9 X_{i}-3475,9 D_{3}-3,4 D_{2} X_{i}+38,1 D_{3} X_{i}, i=1, \ldots, 108 \text { (Equação I), }
$$

em que $X_{\mathrm{i}}$ é a variável tempo e $D_{2}$ e $D_{3}$ são variáveis binárias, codificadas como: 


$$
D_{2}=\left\{\begin{array}{l}
1 \text { se } \quad 73 \leq i \leq 93 \\
0 \text { se } i<73 \text { ou } i \geq 93
\end{array} \text { e } D_{3}=\left\{\begin{array}{l}
1 \text { se } i \geq 93 \\
0 \text { se } i<93
\end{array}\right. \text {. }\right.
$$

$D_{2}$ e $D_{3}$ são variáveis indicadoras;

$X_{\mathrm{i}}$ é a variável tempo.

Obs.: Lembrando-se de que $\hat{Y}$ não faz previsão para $Y$, mas sim para $\mathrm{E}(\mathrm{Y})$.

Tabela 2

Ajuste da Regressão Múltipla com Quebra Estrutural, $R^{2}$ Adjusted = 0,9809

\begin{tabular}{l|c|c|c|c|c}
\hline Variável & $\begin{array}{c}\text { Graus de } \\
\text { Liberdade }\end{array}$ & Estimativas & Erro Padrão & Estatística t & Prob. $>|\mathbf{t}|$ \\
\hline Tempo & 1 & 31,9 & 0,8 & 40,2 & $<0,0001$ \\
$D_{3}$ & 1 & $-3.475,9$ & $1.543,5$ & $-2,3$ & 0,0264 \\
$D_{2}{ }^{*}$ Tempo & 1 & $-3,4$ & 1,1 & $-3,1$ & 0,0023 \\
$D_{3}^{*}$ Tempo & 1 & 38,1 & 15,4 & 2,5 & 0,0148 \\
\hline
\end{tabular}

Elaboração dos autores.

\section{Resultados}

Na série mensal de ocorrências de crimes violentos na cidade de Belo Horizonte, consideraram-se três momentos distintos: período 1 (jan./1995 a dez./2000, período de referência); período 2 (jan./2001 a set./2003, período de intervenção); período 3 (out./2002 a dez./2003, período de retorno ao policiamento tradicional executado no período 1). Ao se observar uma tendência de crescimento das ocorrências quase-lineares, optou-se por estimar um modelo de regressão linear com variáveis indicadoras para incorporar essas distintas formas de policiamento em relação ao período de referência fixado no período 1.

Como se pode verificar a partir da Equação I, o modelo foi expresso significativamente como uma função do tempo (variável $X$ ), do período de retomada do policiamento tradicional (variável $D_{3}$ ), da interação entre o período de intervenção e o tempo (interação $D_{2}{ }^{*} X$ ) e da interação entre o período de retomada do policiamento tradicional e o tempo (interação $D_{3}^{*} X$ ). Nesse caso, três possíveis situações podem ser verificadas: a) como se comporta o ajuste do modelo no período 1 , desconsi- 
derando os momentos subseqüentes ( $D_{2}$ e $D_{3}$ iguais a zero); b) qual é o impacto que o programa teve em relação ao período imediatamente anterior; c) o que ocorreu quando o programa foi "abandonado", retornando à forma tradicional de policiamento.

O gráfico resultante após o ajuste do modelo é o seguinte:

\section{Gráfico 2}

Modelo de Regressão Ajustado para o Período de Intervenção

(Polícia de Resultados)

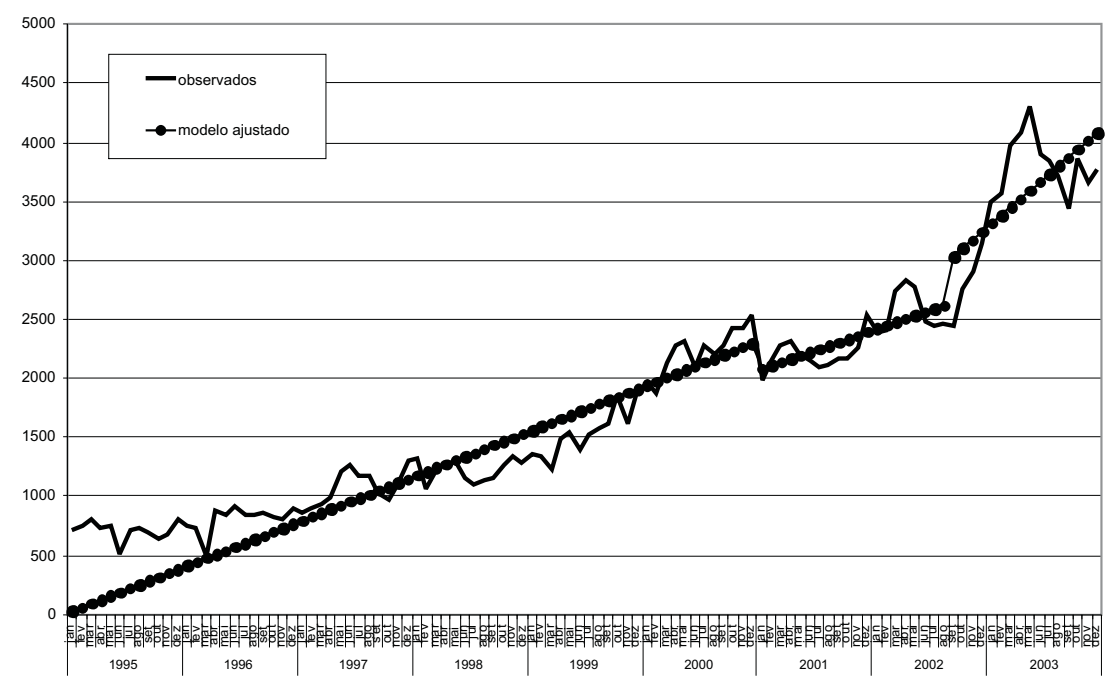

Elaboração dos autores.

Conforme a significância dos parâmetros do modelo apresentados na Tabela 2, podem-se deduzir as seguintes explicações: em um primeiro momento (período 1), percebe-se que ocorre um incremento de aproximadamente 32 crimes violentos para cada unidade de tempo. No momento em que ocorre uma alteração da forma de policiamento (período 2), o número de crimes violentos tende a reduzir, em média, 3,4 crimes para cada unidade de tempo. Quando se retorna à forma tradicional de policiamento (período 3), espera-se um aumento de 38 crimes, em média, para cada unidade de tempo subtraído por uma constante de 3.476 crimes. Isso equivale a dizer que, em relação à série de crimes, o período em que o programa de policiamento estava implementado foi aquele em que se verificou diminuição no número de crimes violentos na cidade de Belo Horizonte. Ao mesmo tempo, verifica-se que o abandono do programa (período 3) fez com que a tendência de cresci- 
mento se tornasse muito mais acelerada se comparada aos períodos anteriores (períodos 1 e 2).

\section{Quantos Crimes Foram Evitados pelo Projeto?}

Se a afirmação anterior é verdadeira, pode-se então quantificar exatamente a redução alcançada pelo programa calculando o número de crimes previstos, se não houvesse nenhuma intervenção, menos o número de crimes efetivamente ocorridos. A diferença entre os valores previstos pela projeção do modelo ajustado no período 1 e os valores observados no período 2 nos fornece a dimensão exata do número de crimes evitados pela introdução do projeto. Procedendo assim, chega-se a uma cifra da ordem de cerca de 5.675 crimes violentos evitados, correspondente à área destacada no Gráfico 3.

Adotando o mesmo procedimento, estima-se o número de crimes que poderiam ter sido evitados posteriormente se o projeto tivesse continuado. Projetando a tendência estimada e diminuindo o valor previsto pelo valor observado, tem-se uma impressionante cifra de 11.073 crimes violentos que poderiam ter sido evitados se o programa tivesse

Gráfico 3

Modelo de Regressão Ajustado Caso o Projeto Não Tivesse Existido

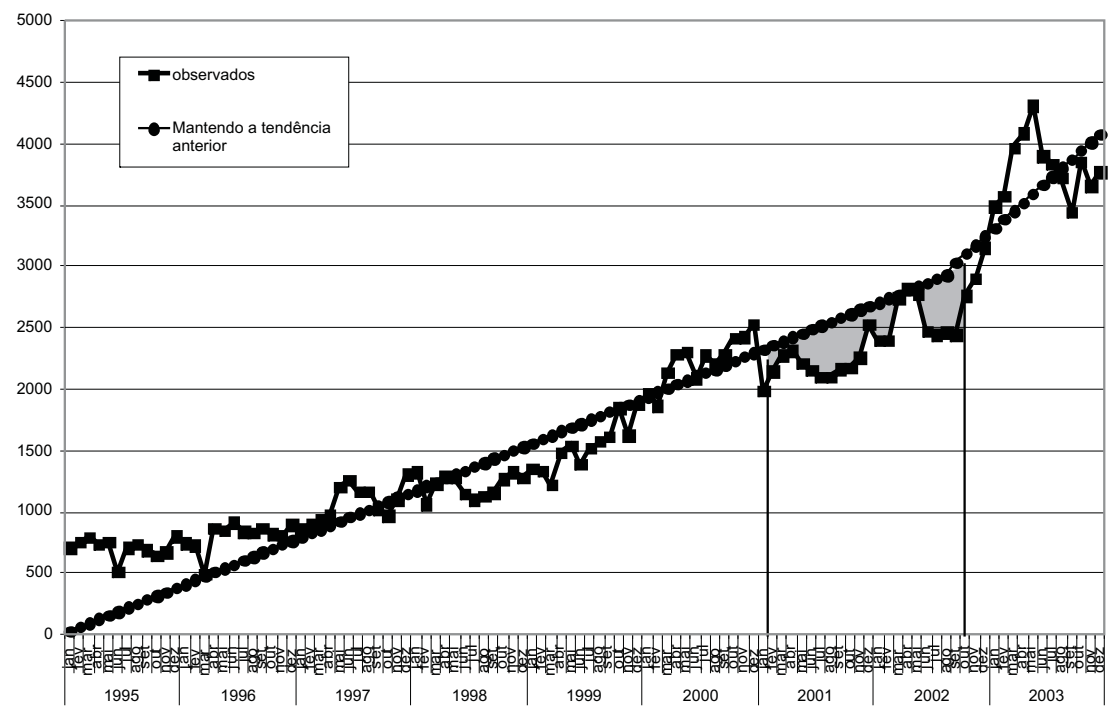

Elaboração dos autores. 
Gráfico 4

Modelo de Regressão Ajustado para a Continuidade Hipotética do Projeto

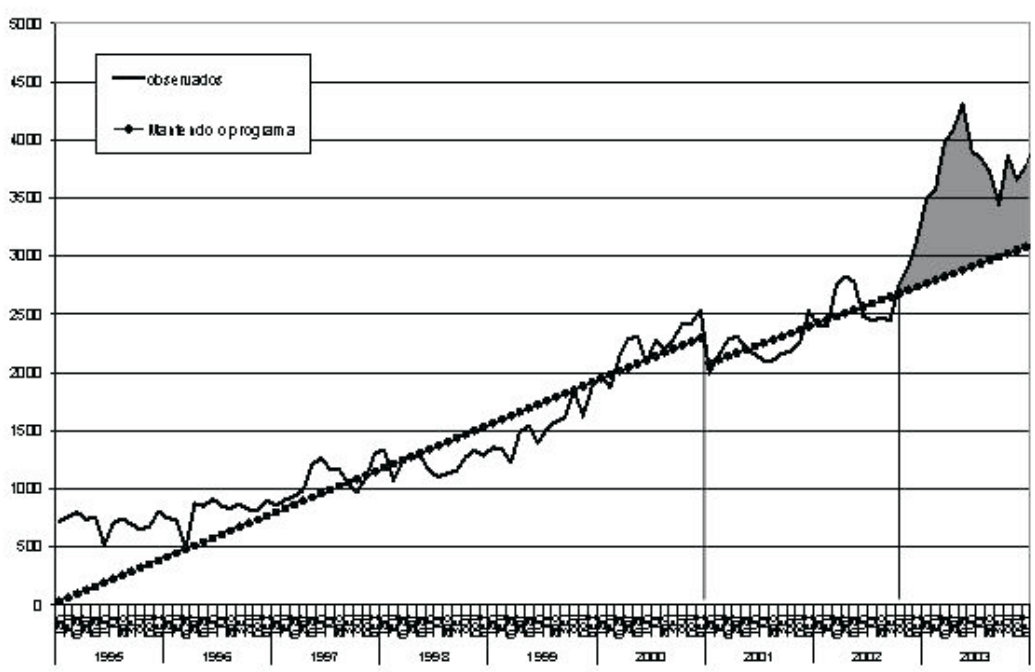

Elaboração dos autores.

continuado nas mesmas condições em que foi implementado. Esse é o número estimado a partir da área escura do Gráfico 4 .

A discussão desse número, entretanto, não é conclusiva, porque não é possível isolar esse resultado do contexto político no qual ocorre o abandono do projeto. No caso brasileiro, esse é um período de campanhas eleitorais para presidência e, especialmente, para governadores, que são os responsáveis políticos das polícias. O efeito de ciclos eleitorais sobre a segurança pública pode caminhar na direção oposta ao que tem sido observado em outros países (Levitt, 2002). No caso do Brasil, em virtude da politização das polícias, este pode ser um momento de desestruturação e desagregação das condições de segurança em vez de controle maior sobre a criminalidade.

\section{CONSIDERAÇÕES FINAIS}

Analisou-se a evolução do número de crimes violentos na cidade de Belo Horizonte em três períodos. O primeiro se refere a um crescimento vegetativo do número de crimes de 1995 até dezembro de 2000. Durante esse ano teve início uma série de transformações a fim de organizar as informações e implementar as modificações pretendidas. Os efeitos dessa forma de gestão por resultados já se fazem sentir nos primei- 
ros meses de 2001, quando se inicia um período de decréscimo e de estabilidade do ritmo de crescimento dos crimes violentos. Tal estabilidade persiste até o começo do terceiro período, quando há a retomada de formas tradicionais de policiamento. O resultado é que em pouco mais de oito meses assistimos a um aumento de até $71 \%$ dos crimes violentos. Os homicídios aumentaram a uma razão de mais de $50 \%$ em um ano. Isso levou a uma retomada dos processos gerenciais anteriormente descritos dentro de uma articulação mais ampla de organizações e agências envolvidas. Essa segunda fase não foi objeto de análise, embora os resultados sejam ainda mais positivos e merecedores de uma análise posterior.

Trata-se de números que merecem uma análise mais cuidadosa. Poderíamos estar assistindo à concorrência de outros fatores intervenientes associados a essa mudança da tendência temporal observada. Algumas hipóteses sugeridas pela literatura para a explicação do crescimento da criminalidade violenta poderiam ser representadas esquematicamente da seguinte maneira:

\section{Desigualdades, Processos Sociais e Violência}

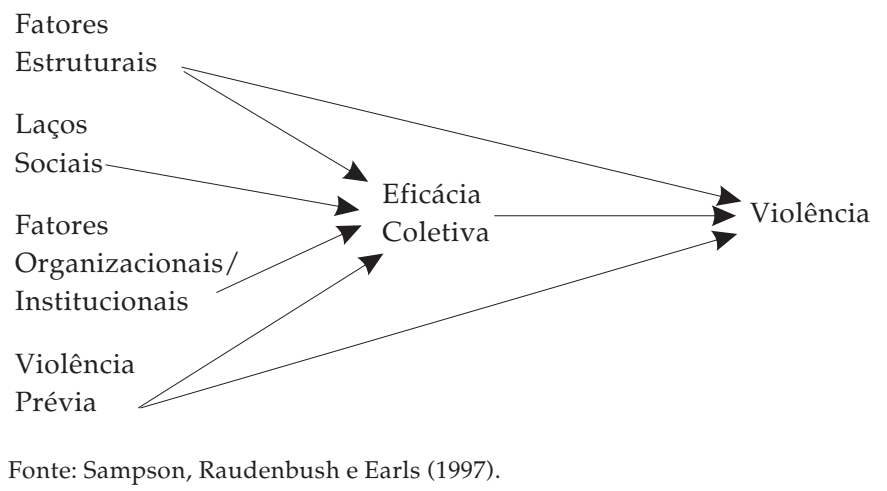

Fatores estruturais dizem respeito ao contexto macroeconômico, aumento de desemprego, modificações na estrutura etária, desigualdade, industrialização etc. Embora não tenha ocorrido um controle sistemático dessa ordem de fatores, podemos afirmar que não houve nenhuma alteração significativa dessa magnitude durante o período. Não foram observados surto extraordinário de industrialização, desestruturação de laços comunitários eventualmente existentes ou alguma mudança brusca na estrutura etária. O desemprego manteve-se 
nos mesmos patamares. Nada parece indicar que tenha havido um aumento significativo do consumo ou do comércio de drogas ilegais. As outras organizações que compõem o sistema de justiça continuaram a funcionar de forma tão lenta e ineficiente como sempre o fizeram. Prisões continuavam abarrotadas e sem vagas como sempre. Os locais violentos seguiram mantendo os mesmos padrões de violência prévia, mesmo que alguns até os tenham diminuído. O grande fator que sofreu mudanças foi a gestão específica das formas de policiamento ostensivo, que passou a ser orientada por dados, dentro de uma metodologia de solução de problemas por meio de informações.

A controvérsia acerca do impacto que formas de policiamento têm sobre as taxas de criminalidade incorporou, em anos recentes, a importância da reengenharia gerencial como fator crucial para explicar o efeito da polícia sobre o crime. Buscamos argumentar nessa direção ressaltando a importância do policiamento orientado para problemas e guiado por dados e informações. Assim, a importância da gestão de informações que incorporem elementos ambientais e de contexto urbano é elemento essencial desse processo gerencial. A descentralização de planejamento e organização de informações incorpora variáveis ambientais para o desenvolvimento de soluções e resultados, conduzindo a uma simbiose importante entre contexto urbano e organização policial. O conceito de "policiamento orientado por dados" deve incorporar dimensões urbanas para o planejamento e a alocação de recursos e para a definição de "áreas quentes" (hot spots) a fim de compartilhar com outros setores da administração pública soluções e estratégias de resolução de problemas.

Políticas e programas em segurança pública que não levem em conta aspectos de contexto urbano e se atenham simplesmente às variáveis macroestruturais e socioeconômicas tendem a criar grande grau de paralisia institucional. Daí a necessidade de as organizações policiais passarem a atuar de forma articulada entre si e outros órgãos da administração pública. Estratégias de redução de oportunidades e de design ambiental requerem a análise de fatores ambientais e urbanísticos para sua implementação.

Nessa fase da experiência narrada, os resultados alcançados poderiam ter sido muito mais significativos se houvesse a participação de outros órgãos e agências. A participação restrita à polícia militar determinou o pouco alcance dos resultados obtidos, pois os mecanismos gerenciais 
limitavam-se apenas ao âmbito do policiamento ostensivo, não alcançando a esfera da polícia judiciária ou da justiça. Conseqüentemente, os resultados, embora fossem importantes e significativos, poderiam ter sido muito mais impactantes do que os observados nesse período.

Para reforçar esse argumento, deve-se adicionar o que ocorre posteriormente ao estágio de deterioração da experiência inicial. Tão logo se percebe o que estava ocorrendo, há uma retomada das estratégias de gestão por resultados, agora em uma perspectiva mais ampla, por meio do projeto Integração da Gestão de Segurança Pública - Igesp. Ali passam a compor o grupo outras agências e organizações que compõem o sistema de defesa social, como a Polícia Civil e o Ministério Público. Essa segunda fase do projeto não foi objeto de análise, mas tenciona alcançar resultados mais positivos em virtude da introdução de mecanismos gerenciais de gestão de informação e de alocação de recursos pela análise dos contextos urbanos dos problemas que ocorrem (Beato F. et alii, 2007).

Dessa forma, buscou-se com este estudo mostrar o que técnicas de gerenciamento com base em resultados, firmadas no uso sistemático de informações, são capazes de produzir em termos de controle da criminalidade. As conclusões para policy makers são óbvias e caminham na direção de se fortalecerem experiências de policiamento preventivo em vez das ações repressivas tradicionais que têm caracterizado a atuação policial no Brasil. Mesmo o que é tradicionalmente concebido como estratégia preventiva - o policiamento ostensivo -, é pouco eficaz e nada tem a ver com formas proativas de policiamento que lidam com a solução de problemas. Conceitos como policiamento em áreas quentes, orientados por problemas e guiados por dados, passam a ser centrais dentro dessa nova perspectiva de policiamento (Weisburd e Braga, 2006).

Possivelmente o impacto desse modo de gestão do policiamento seja diferenciado para tipos específicos de criminalidade. Em uma análise complementar, foi observado um efeito maior sobre os crimes contra o patrimônio. Em parte isso ocorreu porque muitas das estratégias específicas desenvolvidas eram de redução de oportunidades. Entretanto, o mesmo tipo de mecanismo pode ser aplicado para a solução de problemas de outra ordem, tais como o dos homicídios envolvendo jovens ${ }^{9}$. 
Outro mérito deste artigo é ser a primeira análise sistemática feita na América Latina sobre o impacto da polícia e de formas de policiamento nas taxas de criminalidade em contextos urbanos. A abordagem ecológica com a utilização de informações mapeadas de crimes permitiu um exame detalhado das condições dessa intervenção e de seu impacto em um grande centro urbano. São possibilidades bastante alentadoras no desenvolvimento de políticas públicas e promissoras no âmbito da investigação acadêmica.

(Recebido para publicação em junho de 2007)

(Versão definitiva em novembro de 2007)

\section{NOTAS}

1. Um dos projetos centrais foi o MAPA, de Belo Horizonte, que consistiu em uma parceria do Crisp, da Universidade Federal de Minas Gerais - UFMG, com o Comando de Policiamento da Capital -CPC, da PMMG. Ele foi parte de um programa mais amplo implementado pelo CPC: o Polícia de Resultados. Esse programa buscou introduzir novas técnicas de gerenciamento das atividades policiais mediante a descentralização do planejamento de operações e a introdução de mecanismos de aferição e controle de resultados.

2. Para uma avaliação do programa de policiamento comunitário em Belo Horizonte, ver Beato F. (2004b).

3. O software da base de dados foi desenvolvido pela Companhia de Tecnologia da Informação do Estado de Minas Gerais - Prodemge. Os softwares para a tradução desses dados para fins de visualização e análise espacial foram inicialmente desenvolvidos pelo Crisp, da UFMG.

4. Em 1992, a Prodabel propiciou à Prefeitura de Belo Horizonte um dos primeiros Sistemas de Informações Geográficas de dados municipais.

5. Mais recentemente, uma empresa privada passou a fornecer também bases de dados de fotos aéreas georreferenciadas de toda a cidade de Belo Horizonte.

6. Esse curso totalizou 60 horas-aula e foi composto por dois módulos: um relativo ao uso do software MapInfo@ para geoprocessamento de eventos criminosos e outro para o uso de algumas ferramentas de estatística descritiva de dados criminais. Em outra etapa, o mesmo curso foi dado para cerca de quarenta policiais oriundos das companhias de policiamento e envolvidos mais diretamente em atividades de policiamento de ponta. Duas formas de utilização foram desenvolvidas: geoprocessamento das ocorrências e análise estatística dos delitos.

7. Alguns policiais da PMMG, patrocinados pela Fundação Ford, foram a Nova York conhecer essa experiência.

8. Ver nota metodológica em Anexo.

9. Ver Beato F. $(2000 ; 2004 c)$. 


\section{REFERÊNCIAS BIBLIOGRÁFICAS}

ABOTT, Andrew. (1997), "Of Time and Space: The Contemporary Relevance of the Chicago School". Social Forces, vol. 75, no 4, pp. 1149-1182.

BAILEY, William C. (1984), "Poverty, Inequality and City Homicides Rates". Criminology, vol. 22, no 4 , pp. 531-550.

BAYLEY, David H. (1994), Police for the Future. Oxford, Oxford University Press.

BEATO F., Claudio C. (2000), “Determining Factors of Criminality in Minas Gerais”. Brazilian Review of Social Sciences, vol. 1, pp. 159-173.

. (2001), “Acción y Estrategia de las Organizaciones Policiales”, in H. Frühling e A. Candina (eds.), Policía, Sociedad y Estado: Modernización y Reforma Policial en America del Sur. Santiago, Centro de Estudios para el Desarrollo, pp. 39-56.

. (2004a), Auditoria e Gestão da Informação em Segurança Pública. Curso para Gestores Municipais. Washington/São Paulo, Banco Mundial (World Bank).

. (2004b), “Reinventar la Policía: La Experiencia de Belo Horizonte”, in H. Frühling (ed.), Calles Más Seguras: Estudios de Policía Comunitaria en América Latina. Washington, Inter-American Development Bank, pp. 100-134.

. (2004c), "Fica Vivo: Projeto de Controle de Homicídios em Belo Horizonte". Washington, D.C., World Bank. (Estudo de Casos).

e REIS, Ilka A. (1999). “Desigualdade, Desenvolvimento socioeconômico e Crime”. Trabalho apresentado no seminário sobre Desigualdade e Pobreza no Brasil, realizado pelo IPEA, 12-14 de agosto.

BEATO F., Claudio C., VIEGAS, Mônica e PEIXOTO, Betânia T. (2004), “Crime, Oportunidade e Vitimização”. Revista Brasileira de Ciências Sociais, vol. 19, n. 55, pp. 73-89.

BEATO F., Claudio C. et alii. (1999), Criminalidade Violenta em Minas Gerais: 1986-1997. CD-ROM.

. (2001), “Conglomerados de Homicídios e o Tráfico de Drogas em Belo Horizonte, Minas Gerais, Brasil, de 1995 a 1999". Cadernos de Saúde Pública. Rio de Janeiro, vol. 17, n. 5, pp. 1163-1171.

. (2005), Zip Law e Hot Spots de Crime em Belo Horizonte. Belo Horizonte, UFMG. Mimeo.

. (2007), "IGESP, Integração e Gestão de Segurança Pública”. Informativo Crisp, ano 5, no 7. Disponível em http://www.crisp.ufmg.br/informa.htm.

BLAU, Judith R. e BLAU, Peter M. (1982), “The Cost of Inequality: Metropolitan Structure and Violent Crime". American Sociological Review, vol. 47, no 1, pp. 114-129.

BLUMSTEIN, Alfred, COHEN, Jacqueline e NAGIN, Daniel (eds.). (1978), Deterrence and Incapacitation: Estimating the Effects of Criminal Sanctions on Crime Rates. Washington, D.C., National Academy Press.

BOTTOMS, Anthony E. e WILES, Paul. (1997), "Environment Criminology", in M. Maguirre, R. Morgan e R. Reiner (eds.), The Oxford Handbook of Criminology. Oxford, Oxford University Press. 
BOYDSTUN, John E. (1975), San Diego Field Interrogation: Final Report. Washington, D.C., Police Foundation.

BRATTON, William. (1998), Turnaround: How America's Top Cop Reversed the Crime Epidemic. New York, Random House.

BURSIK JR., Robert J. (1986), “Ecological Stability and the Dynamics of Delinquency”, in A. J. Reiss Jr. e M. Tonry (eds.), Communities and Crime. Chicago/London, University of Chicago Press.

CHOW, Gregory C. (1960). “Tests of Equality Between Sets of Coefficients in Two Linear Regressions". Econometrica, vol. 28, n으 3, pp. 591-605.

COHEN, Lawrence e FELSON, Marcus. (1979), "Social Change and Crime Rate Trends: A Routine Approach". American Sociological Review, vol. 44, no 4, pp. 588-608.

CRISP - Centro de Estudos de Criminalidade e Segurança Pública. (2000), Atlas da Criminalidade em Belo Horizonte. Belo Horizonte, Crisp/UFMG.

DATASUS - Departamento de Informática do SUS. (2007), Sistema de Informações sobre Mortalidade do Ministério da Saúde. Disponível em http://www.datasus.gov.br.

DAVIS, Mike. (1998), Ecology of Fear. London, Picador.

DURKHEIM, Émile. (1978), “Da Divisão do Trabalho Social”, in Os Pensadores. São Paulo, Abril Cultural.

FAJNZYLBER, Pablo, LEDERMAN, Daniel e LOAYZA, Norman. (1998), “Determinants of Crime Rates in Latin America and the World". Washington, D.C., World Bank. (Latin American and Caribbean Studies).

FREITAG, Barbara. (2002), Cidade dos Homens. Rio de Janeiro, Tempo Brasileiro.

GOLDSTEIN, Herman. (1990), Problem-Oriented Policing. New York, McGraw-Hill.

IBGE - Instituto Brasileiro de Geografia e Estatística. (2004), Censo Demográfico 2000. Rio de Janeiro, IBGE.

JACOB, Herbert e RICH, Michael J. (1980), “The Effects of the Police on Crime: A Second Look". Law \& Society Review, vol. 15, no 1, pp. 109-122.

JOHNSON, Bruce et alii. (1990), "Drug Abuse in the Inner City: Impact on Hard-Drug Users and the Community", in J. Q. Wilson e M. Tonry. Drugs and Crime. Crime and Justice. Chicago/London, University of Chicago Press, pp. 9-67, vol. 13.

KELLING, George L. e COLES, Catherine M. (1996), Fixing Broken Windows: Restoring Order and Reducing Crime in our Communities. New York, Touchstone.

KELLING, George L. et alii. (1974), "The Kansas City Preventive Patrol Experiment: A Summary Report", in D. H. Bayley (ed.), What Works in Policing. New York/Oxford, Oxford University Press.

LAND, Kenneth C., MCCALL, Patricia L. e COHEN, Lawrence E. (1990), “Structural Covariates of Homicide Rates: Are there Any Invariances across Time and Social Space?". American Sociological Review, vol. 95, no 4, pp. 922-963.

LEVITT, Steven D. (2002), “Using Electoral Cycles in Police Hiring to Estimate the Effect of Police on Crime". The American Economic Review, vol. 87, no 3, pp. 270-290. 
LOFTIN, Colin e MCDOWALL, David. (1982), “The Police, Crime, and Economic Theory: An Assessment". American Sociological Review, vol. 47, pp. 393-401.

MANNING, Peter K. (1988), Symbolic Communication. Signifying Calls and the Police Response. Cambridge, The MIT Press.

. (1992), "Information Technologies and the Police", in M. Tonry e N. Morris (eds.), Modern Policing. Crime and Justice. Chicago/London, University of Chicago Press, vol. 15 .

MUIR JR., William Ker. (1977), Police: Streetcorner Politicians. Chicago, University of Chicago Press.

PARK, Robert E. e BURGESS, Ernest W. (1924), Introduction to the Science of Sociology (2a ed.). Chicago, University of Chicago Press.

PATE, Anthony et alii. (1985), Reducing the Signs of Crime. Washington, D.C., Police Foundation.

REISS JR., Albert J. e BORDUA, David. (1966), “Charisma, Bureaucracy and Leadership in Policing". American Journal of Sociology, vol. 72, n ․ 1, pp. 67-78.

SAMPSON, Robert J. (2002), "Transcending Tradition: New Directions in Community Research, Chicago Style". Criminology, vol. 40, no 2, pp. 213-230.

e COHEN, Jacqueline. (1988), “Deterrent Effects of the Police on Crime: A Replication and Theoretical Extension". Law \& Society Review, vol. 22,nํ1, pp. 163-190.

SAMPSON, Robert J., RAUDENBUSH, Stephen W. e EARLS, Felton. (1997), “Neighborhoods and Violent Crime: A Multilevel Study of Collective Efficacy". Science, vol. 277, no 5.328 , pp. 918-924.

SAMPSON, Robert J., MORENOFF, Jeffrey e GANNON-ROWLEY, Thomas. (2002), "Assessing 'Neighborhood Effects': Social Processes and New Directions in Research". Annual Review of Sociology, vol. 28, pp. 443-478.

SCHUERMAN, Leo e KOBRIN, Solomon. (1986), “Community Careers in Crime”, in M. Tonry e N. Morris (eds.), Crime and Justice. Chicago, University of Chicago Press, vol. 8 .

SHAW, Clifford R. e MCKAY, Henry D. (1942), Juvenile Delinquency and Urban Areas. Chicago, University of Chicago Press.

SHERMAN, Lawrence W. (1983), "Patrol Strategies for Police”, in J. Q. Wilson (ed.), Crime and Public Policy. San Francisco, ICS Press.

GARTIN, Patrick R. e BUERGER, Michael E. (1989), "Hot Spots of Predatory Crime: Routine Activities and the Criminology of Place". Criminology, vol. 27, nn 1, pp. 27-55.

SILVA, Bráulio Figueiredo A. da. (2004), Coesão Social, Desordem Percebida e Vitimização em Belo Horizonte, Minas Gerais, Brasil. Dissertação de mestrado, Programa de Sociologia, UFMG.

SKOLNICK, Jerome H. (1966), Justice without Trial. New York, John Wiley.

WEBER, Max. (1978), Economy and Society. Berkeley, University of California Press. 
WEISBURD, David e BRAGA, Anthony (eds.). (2006), Police Innovation: Contrasting Perspectives. Cambridge, Cambridge Univeristy Press.

WILSON, James Q. (1968), Varieties of Police Behavior. Cambridge, Harvard University Press.

e BOLAND, Barbara. (1982), "The Effects of the Police on Crime". Law \& Society Review, vol. 12, no 3, pp. 367-390.

WILSON, James Q. e KELLING, George L. (1982), “Broken Windows: The Police and Neighborhood Safety". Atlantic Monthly, vol. 249, no 3, pp. 29-38.

WILSON, William Julius. (1987), The Truly Disadvantaged: The Inner City, the Underclass, and Public Policy. Chicago, University of Chicago Press.

ZALUAR, Alba. (1984), Condomínio do Diabo. Rio de Janeiro, Revan/Ed. UFRJ.

ZILLI, Felipe. (2004), Violência e Criminalidade em Vilas e Favelas dos Grandes Centros Urbanos: Um Estudo de Caso da Pedreira Prado Lopes. Dissertação de mestrado, Programa de Sociologia, UFMG. 


\section{ANEXO \\ TESTE DE CHOW}

\section{Testando Quebra Estrutural em Pontos Conhecidos}

Considere que a amostra seja dividida em duas subamostras, uma contendo as observações antes do ponto de mudança e outra o restante das observações após o ponto de mudança.

Suponha o modelo hipotético abaixo para explicarmos a idéia do teste:

$$
\begin{aligned}
Y_{i}=\beta_{0}+\beta_{1} X_{1 i}+\beta_{2} X_{2 i}+\varepsilon_{i}, & i=1, \ldots, N . \\
\varepsilon_{i} & \sim N I\left(0, \sigma_{\varepsilon}^{2}\right) .
\end{aligned}
$$

A hipótese nula do teste é que não existe mudança nos parâmetros do modelo e a alternativa é que ao menos um dos parâmetros mudou em algum instante do tempo.

$\mathrm{H}_{0}$ : Os parâmetros $\left(\beta_{0}, \beta_{1}, \beta_{2}\right)$ são constantes em toda a amostra.

$\mathrm{H}_{1}$ : Os parâmetros $\left(\beta_{0}, \beta_{1}, \beta_{2}\right)$ mudam em um instante de tempo (ponto de mudança) para $\left(\beta_{0}+\delta_{0}, \beta_{1}+\delta_{1}, \beta_{2}+\delta_{2}\right)$, em que ao menos um $\delta_{i} \neq 0, i=1,2,3$, e permanece constante até o final da amostra.

Na hipótese nula de não existir quebra estrutural, a soma de quadrados residuais dos modelos construídos para cada uma das subamostras $\left(S Q E_{N_{1}}+S Q E_{N_{2}}\right)$ não deve diferir significativamente da soma de quadrados residuais total $\left(S Q E_{N}\right)$ obtida do modelo com a amostra completa.

Essa é a idéia que se oculta sob o teste para quebra estrutural proposto por Chow (1960):

$$
F_{\text {chow }}=\frac{\left(S Q E_{N}-\left(S Q E_{N 1}+S Q E_{N 2}\right)\right) / k}{\left(S Q E_{N 1}+S Q E_{N 2} /(N-2 k)\right.} \sim F_{(k, N-2 k)}
$$

A estatística do teste de Chow tem distribuição $F$ com $k$ graus de liberdade no numerador e $N-2 k$ no denominador, em que $k$ é o número de parâmetros do modelo. Nesse caso, o p-valor do teste é dado como a probabilidade de se obter um valor da estatística de teste maior do que aquele de fato observado. 


\section{ABSTRACT}

\section{Crime and Law Enforcement Strategies in Urban Areas}

The article seeks to explore the interconnections between police, crime, and urban territory, discussing their crucial importance in the current public policy scenario for security in large Brazilian cities. The author draws on observations of a monthly series of violent crimes in Belo Horizonte, Minas Gerais State, in a regression model with structural breaks to estimate the impact of the so-called "Results-Based Police" Program in reducing crime. According to the findings, police intervention in urban territory was responsible for a significant reduction in violent crimes $(5,675)$ from January 2001 to October 2003.

Key words: crime; police; urban territory; "Results-Based Police"; law enforcement program

\section{RÉSUMÉ}

\section{Crime et Stratégies Policières dans l'Espace Urbain}

Dans cet article, on examine le réseau des liens entre la police, le crime et l'espace urbain, dont l'importance reste capitale pour le cadre actuel des politiques publiques concernant la sécurité des grands centres urbains au Brésil. On a pris pour base des observations sur une série mensuelle de crimes violents commis à Belo Horizonte, selon un modèle de régression à coupes structurelles pour évaluer l'impact du programme de "Police à Résultats" sur la réduction de la criminalité. Selon les résultats, on voit, entre autres, que $l^{\prime}$ intervention de la police urbaine a réussi à y diminuer de façon significative le nombre de crimes violents, qui était de l'ordre de 5.675 entre janvier 2001 et octobre 2003.

Mots-clé: crime; police; espace urbain; "Police à Résultats"; programme d'intervention 